\title{
Improving Skills and Character Youth Football Player through Games Experience Coaching Model
}

\author{
Sulistiyono $^{1,2, *}$, Sugiyanto ${ }^{1}$, Agus Kristiyanto ${ }^{1}$, Sapta Kunta Purnama ${ }^{1}$ \\ ${ }^{1}$ Department of Sports Science, Faculty of Sports, Sebelas Maret University, Indonesia \\ ${ }^{2}$ Department of Sports Science, Faculty of Sports Science, Yogyakarta State University, Indonesia
}

Received December 13, 2020; Revised January 16, 2021; Accepted February 24, 2021

\section{Cite This Paper in the following Citation Styles}

(a): [1] Sulistiyono, Sugiyanto, Agus Kristiyanto, Sapta Kunta Purnama, "Improving Skills and Character Youth Football Player through Games Experience Coaching Model," International Journal of Human Movement and Sports Sciences, Vol. 9, No. 2, pp. 171-179, 2021. DOI: 10.13189/saj.2021.090202.

(b): Sulistiyono, Sugiyanto, Agus Kristiyanto, Sapta Kunta Purnama (2021). Improving Skills and Character Youth Football Player through Games Experience Coaching Model. International Journal of Human Movement and Sports Sciences, 9(2), 171-179. DOI: 10.13189/saj.2021.090202.

Copyright $@ 2021$ by authors, all rights reserved. Authors agree that this article remains permanently open access under the terms of the Creative Commons Attribution License 4.0 International License

\begin{abstract}
Coaching in sport is a complex activity where several components influence each other to achieve the goal, especially in team sports. Skills, physical abilities, and tactics are not enough, but with strong character by the players increasingly the chances of achieving team success. Researchers have not found coaching models that aim to improve technical skills and character integrated and proven to be effective. This research aims to find the effectiveness of the games experience learning coaching model to improve passing, receiving, dribbling, shooting technical skills and teamwork, respect, discipline character in a youth football player. This research used experimental methods. The sample was 46 youth football players from some football schools in Sleman District, Yogyakarta Region, Indonesia. Twenty-three players sampled the intervention group and 23 players sampled the control group. Data collection used skill tests for technical skills and observation tests for character players. Skill and character measurements are carried out before and after treatment, where the treatment is carried out for 10 weeks. Data analysis was done with the ANCOVA technique, strengthened by paired t-test using SPSS 22 program. The results of the study are games experience learning base coaching model (1) having a significant influence on technical skills and character youth football player, (2) effective to improve skills and character youth football player. The limitation of this study is the interaction activities of players with peers in the environment, with families that researchers cannot control may influence the results of the study. The games experience learning base
\end{abstract}

coaching model can be an alternative that can be used by football coaches in charge of coaching young players. This coaching model is following the youth positive development policy where sports activities not only think about winning but also attention to attitude, life skills, character that can be a provision for the lives of young athletes in the future. The games- experience learning based coaching model requires improvement in some parts of the game to make skill improvement more optimal.

Keywords Character, Coaching, Football, Game, Skills

\section{Introduction}

Coaching and training policies in sports between countries may be different, but it has the same goal of optimal performance of their elite athletes. The long term athlete development (LTAD) model is a training model that is planned, structured, and progressively improved to prepare athletes for career success at the right time [1], develop their healthy lifestyles, positive attitudes, behaviors, and make them aware of the importance of formal education for living after undergoing a sports career[2]. Concerning coaching for sports competitions, problems of interactions that typically appear may include failures in competitions, physical abilities, skills, and less optimal tactics, but in other perspectives another problem 
exists, the negative behavior of athletes, spectators, and referees. The aggressiveness of athletes, specifically on the type of sports that requires great efforts, triggers disagreeable attempts to dominate the opponents [3].

Technical skills and decision making are two contributing factors that determine the mini players performance in volleyball games [4]. In another study, technical skills and perceptions have a strong relationship with the ability to attack and defend in professional Rugby players [5]. Athletes are required to develop high levels of physical and skill in high-performance sport. In a high-performance setting, skills are obviously expected to be at a superior stage of development to the general population [6]. Talent has athlete in responding to training, skills can be developed with training and each player needs to train for improve these skills [7]. Players who successfully play at a English Premier League club at youth players who have trained for more than 10 years, investing an average of about 15 hours per week, 700 hours per year, and a total of 7000 hours in training activities designed to improve performance [8].

A football player's performance in a match is not only influenced by skill skills, but behavioral factors in matches, exercises, or interactions in life become important for all administrators, coaches, and parents of athletes. Positive youth development (PYD) is a concept used to define the promotion of desirable competencies that lead to positive developmental outcomes for youth [9]. Behaviors that have become habitual can be interpreted as personality or character. Personality influence is significant for player performance during the competition season [10]. Similarly, discussed five key outcomes or objectives of optimal youth development in their $5 \mathrm{C}$ model, these include: character; competence, connection; confidence and caring [11]. In their review paper, many life skills can be developed through sport, with the most commonly cited being emotional, goal setting, time management, teamwork skills, social, and interpersonal communication skills, and problem solving, decision making, leadership skill [12].

Teamwork attitude is a dynamic process involving a collaborative effort by team members to effectively carry out the independent and interdependent behaviors that are required to maximize a team's likelihood of achieving its purposes [13]. Respect, discipline, honesty, and responsible behavior are important things to develop in sports. Respect for teammates, opponents, and others on sports coaching interactions [14]. This view is shared by others that sport has the capacity to challenge and motivate people in ways not found in other life pursuits, such as school or work [15]. Jones and Lavallee [16] found that adolescent athletes considered interpersonal skills and personal skills (as important skills necessary to succeed in life. Furthermore, Peterson [17] concluded that although developmental programs such as sports have the potential to drive positive youth development, it is the personal characteristics of group leaders that are the essential ingredient for the success of all youth development programs.

Develop relationships with athletes, intentionally plan developmental in coaching practice, do not just talk about life skills, make athletes practice life skills, teach how life skills transfer to non-sport settings is a strategy to develop athletes to have positive behavior [18]. Great coaches will always try to give full attention and focus on the team, This spirit of leadership is needed so that it can produce something positive in a team,[19]. However, researchers found that practical solutions related to character development in sports coaching settings achieved relatively a little. Some research on the development of attitudes, behaviors, or life skill through sports activity is found in many sports education settings. Cooperative learning was significantly more effective than classical learning to develop moral value, [20]. Physical education model of teaching personal and social responsibility [21] had been aimed to develop responsibility. The sports united to promote education and recreation (SUPER) is a program designed to develop life skills through sports playing activities [22]. Strachan, Mac Donald, \& Cote [23], [24] argue that connect and respect sports (SCORE) is a physical activity and physical education designed to develop the attitude and behavior of students.

Studies of integrated exercises aimed at developing the skills and behaviors or character of young footballers in a comprehensive training environment have not been found. Based on the conditions that occurred this study aims to (1) design an coaching model that integrates character values in the training process, not only developing skills at football schools, (2) test the effectiveness of the game experience learning coaching model. Thus, the current study offers a possibly effective and verified solution to the gap by developing a training model based on the game experience learning to improve the skills and character football players aged 9-12. The skills that are expected to improve are passing, receiving, dribbling and shooting, while the expected characters are teamwork, respect, and discipline.

\section{Material and Method}

The study applied experiment design with two groups: the experiment group and the control group. Group A (experiment), the group that intervention games experience learning coaching model, and group B (control) that conventional or regular coaching models. At the beginning of the study developed a games experience learning coaching model to be implemented in the experiment group, while the control group used conventional training programs. The games experience learning coaching model is the result of Research \& Development studies that have been validated by experts. 
Validation with Aiken technique with a score of 4.46 (very good), the experiment design is shown in Figure 1. Forty-Six youth football player at Sleman football school were selected and willing to sample this research. The sample had male gender characteristics, height means $140.98 \mathrm{~cm}, \mathrm{SD}=5.41$, weight mean $34.33 \mathrm{~kg}$, $\mathrm{SD}=6.68$, with ages 10-12 years (Mean= 11.6 Years, $\mathrm{SD}=0.87$ ).

\begin{tabular}{|l} 
Experiment Group : A------------------X1-------------A1 \\
Control Group $\quad$ : B---------------X2-----------B1 \\
\hline
\end{tabular}

Figure 1. Experiment Design

A, B : initial pre-test skill and character

A1, B : initial pos test skill and character

X1 : Games Experience Learning intervention for Experiment Group

X2 : Conventional treatment for Control Group

------: Coaching Period

Researchers developed skill and character instrument where their validity was tested with Aiken validation techniques. Skill instruments were developed to assess passing, receiving, dribbling, and shooting skills, validity index of instrument skill test result 0.85 . Passing skills test: The player pass the ball on target $0.5 \times 2 \mathrm{~m}$ using right foot 5 time, and using left foot 5 time. The ball that makes it to the target is given a score of 1 so that the maximum score obtained by the player on the passing skill test is 10 points. Receiving skill test: the player kicks and receives the ball towards the wall as quickly as possible within 30 seconds. The distance of players to the wall is at least 4 meters, with a target of $0.6 \mathrm{~m} \mathrm{x} 3 \mathrm{~m}$ area. The number of balls successfully received and passed is recorded and becomes a skill score of receiving the ball. Dribbling skill test: the player dribbles past the established signs quickly as possible. Players are given two chances of doing tests and the best results in second are used dribbling skill test results. Shooting skill test: the player shoot towards the goal with a size of $2 \times 5 \mathrm{~m}$ which is divided into 5 areas. The distance between the kicking area at the goal is $13 \mathrm{~m}$, and the player has a chance to kick 4 time using the right foot, 4 time using the left foot. The maximum score that can be achieved is 400 and a minimum of 0 .

A measuring tool for assessing characters uses observation guidelines performed by coaches. Teamwork characters contain 12 items of statement, respect character contain 12-item characters, and discipline characters of 8 items on a never-always Lickert scale. An example of the "He retaliates against abusive treatment by opponents". The instrument character has a validity of 0.87 . Observations made by the coaches are made within 2 weeks before and after treatment. Games experience learning-based coaching models were given training on coach, while coaches who provided training to the control group conducted perception tanning discussions with the research team. Training is given for eight weeks. We administered the results of pre and post-test skill and characters measurements of all samples, then were analyzed using the Ancova test. Furthermore, to determine the effectiveness of the games experience learning model, the data were analyzed using the paired samples t-test. Statistical calculations are assisted by the SPSS 22 software program.

\section{Results}

Researchers devised an exercise model validated with Aiken techniques. The assessment score on the expert validation process was analyzed and obtained a validity score of 4.46 which means the model is worth using. Effectiveness of the games experience learning (GEL) coaching model is presented two items. These include: first, descriptive presentation of the pre and post-test data of the experiment and control groups; second, results of the Ancova and Paired samples t-test. The GEL coaching model of that has been feasible to be tested for effectiveness see table 1. Main exercises 1, 2, 3 aimed at developing skills and characters. The game is a training medium of fun training and motivates players aged 9-12 years. Coaches use experience learning approach to make change in students' competence through experience, reflect, discover and try to apply to the next training session.

The result of an Ancova test with the SPSS 22 is a Sig $(0.00)<(0.05)$ score which means the program shows that there is an interaction between the program and the skills of the football school students, and there is a significant difference in influence between the intervention group and the control group on the skills. Value B in the estimated parameter results showed that conventional programs had a lower score of 3.62 compared to the intervention group with the games experience learning exercise model. This means that there is a significant difference in the score means between the experiment group and the control group in the implementation of the GEL coaching model for skill development. The results of the paired samples t-test reinforce that the GEL coaching model is more effective than conventional programs where sig value. (2-tailed) for the GEL group coaching model 0.00 while control group 0.00 . Mean difference skills before and after control group -3.14 and intervention group -7.00.

The result of an Ancova test with the SPSS 22 is a Sig $(0.00)<(0.05)$ score which means the program shows that there is an interaction between the program and the character of the football school students, and there is a significant difference in influence between the intervention group and the control group on the character. Value B in the estimated parameter results showed that conventional programs had a lower score of 7.83 compared to the intervention group with the games experience learning exercise model. 
Table 1. The Game Experience Learning (GEL) Based Coaching Model

\section{The Game-Experience-Learning Based Coaching Model}

\section{Training Stages}

The training stages or procedures inform coaches or athletes of the steps or stages of the coaching process to be carried out. The training stages include the following activities.

\begin{tabular}{|c|c|c|}
\hline Training Stage & Training Content or Material & Strategy \\
\hline Warming up & Warming up activities & Guided activities \\
\hline Core Training 1 & $\begin{array}{l}\text { A game for the development of a character value } \\
\text { (Designed by researchers) }\end{array}$ & $\begin{array}{c}\text { Experiential learning (playing, reflecting, discovering, } \\
\text { applying) }\end{array}$ \\
\hline Core Training 2 & $\begin{array}{l}\text { A game for developing certain technical skills } \\
\text { (Selected, analyzed, and designed by Researchers) }\end{array}$ & $\begin{array}{c}\text { Experiential learning (playing, reflecting, discovering, } \\
\text { applying) }\end{array}$ \\
\hline Core Training 3 & $\begin{array}{c}\text { Game } 7 \text { on } 7 \text { football plays based on the federation } \\
\text { playing rules }\end{array}$ & Guided plays with at least one playing rule transfer. \\
\hline Cooling down & Cooling down activities & Guided activities \\
\hline
\end{tabular}

\section{Reaction Principles}

This part of the instructional model explains the roles and relationships between coaches and athletes in the training process.

\begin{tabular}{|c|c|}
\hline Training Stage & The Role of the Coach \\
\hline Warming up & Opening the training session and guiding the warm-up activities for the athletes to get ready for the Core Training 1 . \\
\hline Core Training 1 & $\begin{array}{l}\text { Guiding the players to play the designed game and the reflection phase encouraging them for playing, and giving } \\
\text { rewards or punishments according to the game rules. The reflection phase becomes an important momentum that } \\
\text { coaches should use to send a moral, the values of teamwork, respect, and discipline that are chosen and set at daily } \\
\text { practice. The right time for the reflection phase is given authority to the coach based on the situation and conditions in } \\
\text { which the student is playing. }\end{array}$ \\
\hline Core Training 2 & $\begin{array}{l}\text { Guiding the players through the designed game and the reflection phase, encouraging them for playing, and giving } \\
\text { rewards or punishments according to the game rules. The reflection phase becomes an important momentum that } \\
\text { coaches should use to send a message of how the correct engineering skills should be done according to the problems } \\
\text { faced when in the game. The right time for the reflection phase is given authority to the coach based on the situation and } \\
\text { conditions in which the student is playing. }\end{array}$ \\
\hline Core Training 3 & Managing the young players to have 7 on 7 football plays, explaining one formal football game, and giving feedback. \\
\hline Cooling down & Guiding players for the cool-down activities to return the body to normal conditions and closing the training session. \\
\hline
\end{tabular}

\section{Support Systems}

Conditions required to implement the training process, daily training plans, and other learning resources.

\section{Model Impacts}

4.1. Direct impacts (instructional) as specified in the program objectives

4.2. Indirect effects or side effects generated by learning or training.

Table 2. Descriptive Result Pre and Pos Test Skill and Character

\begin{tabular}{cccccc}
\hline \multirow{2}{*}{ Group } & Competence & \multicolumn{2}{c}{ Pre-Test } & \multicolumn{2}{c}{ Pos-Test } \\
\cline { 3 - 6 } & & Mean & SD & Mean & 50.92 \\
Control & Skill & 47.73 & 6.64 & 5.05 \\
Intervention & Skill & 47.23 & 6.57 & 54.23 & 4.68 \\
Control & Character & 40.27 & 6.72 & 40.62 & 4.64 \\
Intervention & Character & 41 & 4.56 & 48.85 & 3.68 \\
\hline
\end{tabular}

Measurements passing, receiving, dribbling, and shooting skills and teamwork, respect, and discipline character of intervention and control groups are carried out before and after intervention. After the administering of the pre and pos test, score recapitulation of the results can be seen as presented in table 2 .

This means that there is a significant difference in the score means between the intervention group and the control group in the implementation of the GEL coaching model for character development. The results of the paired samples t-test reinforce that the GEL coaching model is more effective than conventional programs where sig value. (2-tailed) for the GEL group coaching model 0.00 while the control group 0.694 . Mean difference characters before and after control group -0.34 and intervention group -7.84 . 


\section{Discussion}

The long term athlete development theory [25], are divided into several phases, and athletes aged 9-12 years are in the "learn to train" phase in which young athletes are expected to strengthen their basic skills, attitude, and behavior through sports coaching interactions. The current study aims to effectiveness test a coaching model or program for the comprehensive development of skills and character of young players aged 9-12 years. The development of the game-experience-learning based training program developed by the researchers has been driven by the research reports of small side games (SSG). Small side and conditioning game models which have been effective for improving technical, tactic, and physical skills [26], but the coaching model capacity in improving the players behavior and character has not been examined. Ivanovych [27] play is one approach or method that can be used to learn movement. The method of playing can improve high-level skills. Therefore, the structure of motor learning in game sports should include four steps: stage I, creation of preconditions and familiarization with motor actions; stage II, mastering motor actions; stage III, consolidation and improvement of motor, stage IV, integration of motor actions.

Football games are classified as invasion games. Optimal performance in football requires a certain amount of capacity and one of them is technical skills. Technical skills are essential in the development of young footballers. Technical skills include passing, shooting, dribbling, and receiving. Besides, it is often assumed that the skills that both legs have (that is, two legs) of equally good quality are advantages [28]. Games experience learning based coaching model used games approach and experiential learning method based on data analysis shows effective to improve passing, receiving, dribbling, and shooting skills. The approach to play has the advantage of a more fun exercise atmosphere and motivates the player to practice. Playing games, in addition to increasing motivation in training, creates a feeling of pleasure, and such games that involve physical activeness have existed for thousands of years [29]. Training programs adopting a game approach, therefore, are believed to be significantly better in developing tactical skills and intrinsic motivation than those with a technical approach, while in terms of technical skills, there seem to be no fundamental differences between the two experimental groups [30].

Coaches as leaders should easily learn the game and game design according to the characteristics of 9-12 year olds, where multilateral improvement of skills is recommended. In this regard, Gabbett, et all suggest that exercise-based sports training is effective for improving physical skills and abilities through opportunity-making games for developing technical-skill decision making based on several components, or by any sports games determined by the coaches [5]. Games with fewer players have a better influence on skill improvement,[31]. The results of the present study indicated that three-a-side games provide higher stimulus for physical conditioning and technical improvement than six-a-side games and their use for training young soccer players is recommended,[32].

Approaches in the training process become interesting discussions, traditional model training, discovery learning models, and other training models have specificity. Increasingly specific technical skills require different instructions [32]. Effect models of games-based exercises and on tactics approaches are recommended to teach sports that are game-type and appropriate to develop techniques, understanding, tactical knowledge, and decision making, [33]. Games as learning media, nevertheless, are not always appropriate and effective as their functions focus on the learning objectives set[34]. Games must be designed to be selected and sorted according to the characteristics and objectives of the learning or coaching.

The results of this study differ from the findings stating that the approach of the game is not appropriate for the development of technical skills, but is appropriate for the development of attitudes, behavioral responsibilities, and decision-making [35]. The results showed that GEL-based coaching model are effective for teamwork, respect, and discipline character development. Character teamwork, respect, and discipline aligned with philosophy positive youth development (PYD). Positive youth development in terms of coaching and interaction of sports performance is important, [36]. However, the socio-cultural at high-performance football clubs may the coaches' efforts to develop or promote positive youth development. Coach education courses should help coaches learn how to promote values and life skills to make youth positive development in high-performance sports, [37]. On the other hand, in designing such games for learning, trainers or coaches should consider the athletes cognitive, motivational, affective, and social-cultural aspects [38].

The results of this study are following were through playing players can engage in a variety of activities both physical, cognitive, and affective. Thus, games are the appropriate activities providing great opportunities for children to participate. By utilizing play activities, children learn and develop as individuals and as members of society. These kinds of games have been designed based on the idea that playing activities are right for children, and traditional games can be used as learning media for children [39].

Game sports in teams are implicitly beneficial for character development [40], but generally various negative behaviors of athletes are another problem to solve. Changes in behavior, start from the stages of moral knowledge, moral feeling, to moral action [41]. In this context, the training model developed with playing activities is expected to provide interventions for changing 
one's moral feeling into the good mood and eventually it can become moral actions in training sessions or daily lives. The modification of the traditional game Gobak Sodor or Galasin adapted to the multilateral development of children and the theory of sports education shows that it can support children to develop their social skills, such as responsibility, social attitude, teamwork, communication, and caring, [42].

Character development can be practiced in an interactive environment of training processes and sports matches. Respect behavior can be developed by intervening through game and match rules, and agreements are built through players, coaches, referees, and spectators or parents of athletes [43]. Weinberg and Gould [44]states that extracurricular sports activities have the potential to develop positive behaviors, for several reasons. These results are also in line with the assertion that a person's character is shaped not only by imitation through observation, but can also be taught through sports, sports, and physical activity situations.

Based on research can be determined that the training model has been able to accommodate its goal of delivering the values of teamwork, respect, and discipline. Games designed to require teamwork in strategizing before the game or during the game process [45]. The goal in teamwork in the game is to establish a sense of mutual need and dependency between players so that through teamwork in the game can improve the social behavior shown by the child [46]. Small side games influence awareness, and teamwork behavior in achieving goals, [47], thus in accordance with this study where the design of games experience learning uses the game approach as a tool to improve skills and behavior.

Qian and Clark[48] in line with this, propose a game-based learning approach in efforts to effectively develop the 21st-century skills, consisting of collaboration, communication, critical thinking, and creativity. Besides, the designed training stages in the core training 1 and 2 contain games implemented by using the experiential learning theory as selected by the researchers. The structure of the training is the authority and decision of the coach. Exercise structure is related to confidence and predictive effectiveness to the results or objectives of exercise by the trainer, [49]. The results of the study are following the research of Muhtar et all [50]where through physical education and sports respectful behavior becomes something that has a large percentage to develop [50].

Teachers and coaches as leaders have the opportunity and responsibility to act as models in efforts to develop the predetermined character and skills [51], but they undoubtedly need effective strategies to achieve the learning and training goals. The developed model allows students to learn the theory and practice and assists them in gaining new experience [52]. Similarly, Chavan suggests the model in which students find pleasure and help in improving their learning outcomes [53].
Experiential learning is declared effective for leadership development, especially in situations where students work in teams [54], and it has been used to develop their decision making and ways to deal with uncertainty [55].

Exercise and sports coaching at a young age should result in a reseave in athletes. Here are the factors that affect enjoyment when sporting activities in children: 1) self-referenced competency, 2) competitive excitement, 3) affiliation with peers, 4) effort expenditure, 5) positive parental involvement, 6) other-referenced competency and recognition [56]. The results of this study are in accordance with wiersma [56], where excitement can be achieved by children when competing in games designed by researchers.

\section{Conclusions}

The development of technical skills and character of young footballers cannot be done instantly. Skill and character development requires a long training process to achieve goals. As explained, the purpose of this study is to know the effectiveness of coaching models for the improving of skills and character in youth football player ages 9-12 years. The results showed that coaching models were declared effective to improve passing, receiving, dribbling, shooting skills and teamwork, respect, discipline character.

The results of this study seek to help answer the thinking patterns of administrators, parents, and coaches who have perception that youth athlete development was not important. The substance of the results of this study can be formulated that the process of training football in young players through the game, and the method of games experiential learning is effective to improve technical skills and character youth football players ages 9-12 years. Future research is expected to identify and explore other types of technical and character skills that support youth football players' development. Efforts to find the best models must be made continuously to be applied in the process of youth football training to improve the knowledge, skills, and character.

\section{Acknowledgment}

The authors thanked the Rector, Head of Research and Community Service Institutes, Dean of the Faculty of Sport Science, of Yogyakarta State University, and Prof. Dr. Siswantoyo, Prof. Dr. Wawan S. Suherman, M. Ed, Dr. Harry Yuliarto, Dr. Komarudin, Nova Ariyanto, Wawan Darmawan, S.Pd.Kor, and Andika Wahyu Utomo, for contributions, assessments and suggestions when validation stages. 


\section{REFERENCE}

[1] G. D. Myer et al., "Sport Specialization, Part I: Does Early Sports Specialization Increase Negative Outcomes and Reduce the Opportunity for Success in Young Athletes?," Sports Health, vol. 7, no. 5, pp. 437-442, 2015. doi:10.1177/1941738115598747

[2] A. W. Pichardo, J. L. Oliver, C. B. Harrison, P. S. Maulder, and R. S. Lloyd, "Integrating models of long-term athletic development to maximize the physical development of youth,” Int. J. Sport. Sci. Coach., vol. 13, no. 6, pp. 11891199, 2018. doi:10.1177/1747954118785503

[3] A. H. Naylor and J. M. Yeager, “A 21st-Century Framework for Character Formation in Sports,” Peabody J. Educ., vol. 88, no. 2, pp. 212-224, 2013. doi:10.1080/0161956X.2013. 775878

[4] P. Mahedero, A. Calderón, J. L. Arias-Estero, P. A. Hastie, and A. J. Guarino, "Effects of student skill level on knowledge, decision making, skill execution and game performance in a mini-volleyball Sport Education season," $J$. Teach. Phys. Educ., vol. 34, no. 4, pp. 626-641, 2015. doi:10.1123/jtpe.2014-0061

[5] T. Gabbett, D. Jenkins, and B. Abernethy, "Game-Based Training for Improving Skill and Physical Fitness in Team Sport Athletes,” Int. J. Sports Sci. Coach., vol. 4, no. 2, pp. 273-283, 2009. doi:10.1260/174795409788549553

[6] D. Farrow and S. Robertson, "Development of a Skill Acquisition Periodisation Framework for High-Performance Sport,” Sport. Med., vol. 47, no. 6, pp. 1043-1054, 2017. doi:10.1007/s40279-016-0646-2

[7] K. Davids, D. Araújo, L. Vilar, I. Renshaw, and R. Pinder, “An Ecological Dynamics Approach to Skill Acquisition: Implications for Development of Talent in Sport," Talent Dev. Excell., vol. 5, no. 1, pp. 21-34, 2013.

[8] F. Casanova, "Representativeness of Offensive Scenarios to Evaluate Perceptual- Cognitive Expertise of Soccer Players," Open Sports Sci. J., vol. 5, no. 1, pp. 161-166, 2012. doi:10.2174/1875399x01205010161

[9] L. Strachan, D. J. Macdonald, and J. Co, "Project SCORE! Coaches' perceptions of an online tool to promote positive youth development in sport," Sport Sci. Coach., vol. 11, no. 1, pp. 108-115, 2016. doi:10.1177/1747954115624827

[10] M. S. Allen, I. Greenlees, and M. Jones, "Personality in sport: A comprehensive review," Int. Rev. Sport Exerc. Psychol., vol. 6, no. 1, pp. 184-208, 2013. doi:10.1080/1750984X.20 13.769614

[11] E. Legg, “The purpose of sport: perspectives of players, coaches, parents, and administrators," Manag. Sport Leis., vol. 0, no. 0, pp. 1-13, 2020. doi:10.1080/23750472.2020.1 792800

[12] C. G. Harwood and C. J. Knight, "Parenting in youth sport: A position paper on parenting expertise," Psychol. Sport Exerc., vol. 16, no. P1, pp. 24-35, 2015. doi:10.1016/j.psyc hsport.2014.03.001

[13] D. McEwan and M. R. Beauchamp, "Teamwork in sport: a theoretical and integrative review," Int. Rev. Sport Exerc. Psychol., vol. 7, no. 1, pp. 229-250, 2014. doi:10.1080/175 0984X.2014.932423
[14] M. Vierimaa, M. W. Bruner, and J. Co, "Positive youth development and observed athlete behavior in recreational sport ^ te,” pp. 1-14, 2018.

[15] D. M. Hansen, R. W. Larson, and J. B. Dworkin, "What adolescents learn in organized youth activities: A survey of self-reported developmental experiences,” J. Res. Adolesc., vol. 13, no. 1, pp. 25-55, 2003. doi:10.1111/1532-7795.130 1006

[16] M. I. Jones and D. Lavallee, "Exploring the life skills needs of British adolescent athletes," Psychol. Sport Exerc., vol. 10, no. 1, pp. 159-167, 2009. doi:10.1016/j.psychsport.2008.06 .005

[17] C. Peterson, “Annals of the American Academy of Political and Social Science: Preface,” Ann. Am. Acad. Pol. Soc. Sci., vol. 591, no. January, pp. 6-12, 2004. doi:10.1177/0002716 203260077

[18] M. Camiré, T. Forneris, P. Trudel, and D. Bernard, "Strategies for helping coaches facilitate positive youth development through sport,” J. Sport Psychol. Action, vol. 2, no. 2, pp. 92-99, 2011. doi:10.1080/21520704.2011.584246

[19] M. N. Nasiruddin, M. S. O. Fauzee, I. Sin, and M. N. Omar, "The motivation of football players: The impact of coach leadership style in malaysian sports schools,” Int. J. Hum. Mov. Sport. Sci., vol. 8, no. 4, pp. 124-133, 2020. doi:10.13189/saj.2020.080404

[20] G. Harianto, R. Rusijiono, S. Masitoh, and W. Setyawan, "Collaborative-Cooperative Learning Model To Improve Theology Students' Characters: Is It Efective?," $J$. Cakrawala Pendidik., vol. 39, no. 2, pp. 409-421, 2020. doi:10.21831/cp.v39i2.31272

[21] P. Pozo, A. Grao-Cruces, and R. Pérez-Ordás, “Teaching personal and social responsibility model-based programmes in physical education: A systematic review," Eur. Phys. Educ. Rev., vol. 24, no. 1, pp. 56-75, 2018. doi:10.1177/1356336X16664749

[22] N. Ntoumanis and J. Y. Y. Ng, "Personal and Psychosocial Predictors of Doping Use in Physical Activity Settings : A Meta-Analysis,” pp. 1603-1624, 2014. doi:10.1007/s40279 $-014-0240-4$

[23] L. Strachan, D. J. MacDonald, and J. Côté, “Project SCORE! Coaches' perceptions of an online tool to promote positive youth development in sport," Int. J. Sport. Sci. Coach., vol. 11, no. 1, pp. 108-115, 2016. doi:10.1177/17479541156248 27

[24] L. Strachan, J. Côté, and J. Deakin, “A new view: Exploring positive youth development in elite sport contexts," Qual. Res. Sport. Exerc. Heal., vol. 3, no. 1, pp. 9-32, 2011. doi:10.1080/19398441.2010.541483

[25] I. Balyi and R. Way, Long-term athlete development. Human Kinetics, 2014.

[26] M. Brandes, L. Müller, and A. Heitmann, "Physiological responses, time-motion characteristics and game performance in 4 vs. 4 small-sided games in elite youth soccer players: different number of mini-goals vs. stop-ball," Sci. Med. Footb., vol. 1, no. 2, pp. 126-131, 2017. doi:10.1080/24733938.2017.1283432

[27] N. V. Ivanovych, "Characterization of the four-stage 
structure of the process of learning motor actions in sports games,” Int. J. Hum. Mov. Sport. Sci., vol. 7, no. 4, pp. 8188, 2019. doi:10.13189/saj.2019.070403

[28] S. Bozkurt and V. Kucuk, "Comparing of Technical Skills of Young Football Players According to Preferred Foot,” Int. J. Hum. Mov. Sport. Sci., vol. 6, no. 1, pp. 19-22, 2018. doi:10.13189/saj.2018.060103

[29] M. Brandes, L. Müller, and A. Heitmann, "Physiological responses, time-motion characteristics and game performance in 4 vs. 4 small-sided games in elite youth soccer players: different number of mini-goals vs. stop-ball," Sci. Med. Footb., vol. 1, no. 2, pp. 126-131. doi:10.1080/24733938.2017.1283432.

[30] P. Bujalance-Moreno, P. Á. Latorre-Román, and F. García-Pinillos, “A systematic review on small-sided games in football players: Acute and chronic adaptations,” J. Sports Sci., vol. 37, no. 8, pp. 921-949, 2019. doi:10.1080/02640414.2018.1535821

[31] R. Duarte, N. Batalha, H. Folgado, and J. Sampaio, “Effects of Exercise Duration and Number of Players in Heart Rate Responses and Technical Skills During Futsal Small-sided Games,” Open Sports Sci. J., vol. 2, no. 1, pp. 37-41, 2009.doi:10.2174/1875399x00902010037

[32] A. Katis and E. Kellis, "Effects of small-sided games on physical conditioning and performance in young soccer players,” J. Sport. Sci. Med., vol. 8, no. 3, pp. 374-380, 2009.

[33] M. T. A. Robles, D. Collado - Mateo, C. Fernández Espínola, E. C. Viera, and F. J. G. Fuentes - Guerra, "Effects of teaching games on decision making and skill execution: A systematic review and meta - analysis," Int. $J$. Environ. Res. Public Health, vol. 17, no. 2, 2020. doi:10.3390/ijerph17020505

[34] M. Pivec and O. Dziabenko, "Game-based learning in universities and lifelong learning: 'Uni Game: Social skills and knowledge training' game concept1,” J. Univers. Comput. Sci., vol. 10, no. 1, pp. 14-26, 2004.

[35] P. Kinnerk, S. Harvey, C. MacDonncha, and M. Lyons, “A Review of the Game-Based Approaches to Coaching Literature in Competitive Team Sport Settings,” Quest, vol. 70, no. 4, pp. 401-418, 2018. doi:10.1080/00336297.2018.1 439390

[36] M. A. Whitley, W. V. Massey, M. Camiré, M. Boutet, and A. Borbee, "Sport-based youth development interventions in the United States: A systematic review,” BMC Public Health, vol. 19, no. 1, 2019. doi:10.1186/s12889-019-6387-z

[37] F. Santos, N. Corte-Real, L. Regueiras, L. Strachan, C. Dias, and A. Fonseca, "Portuguese Football Coaches' Role in Facilitating Positive Development Within High Performance Contexts: Is Positive Development Relevant?,” Int. Sport Coaching. J., vol. 4, no. 2, pp. 147-161, 2017. doi:10.1123/iscj.2016-0009

[38] J. L. Plass, B. D. Homer, and C. K. Kinzer, "Foundations of Game-Based Learning,” Educ. Psychol., vol. 50, no. 4, pp. 258-283, 2015. doi:10.1080/00461520.2015.1122533

[39] W. S. Suherman, Dapan, Guntur, and N. R. Muktiani, "Development of traditional children play based instructional model to optimize development of kindergarteners' fundamental motor skill,” Cakrawala Pendidikan., vol. 38, no. 2, pp. 356-365, 2019. doi:10.21831/cp.v38i2.25289

[40] G. Dishon, "Games of character: team sports, games, and character development in Victorian public schools, 1850 1900," Paedagog. Hist., vol. 53, no. 4, pp. 364-380. doi:10.1080/00309230.2016.1270339.

[41] M. A. Pike, P. Hart, S. A. S. Paul, T. Lickona, and P. Clarke, "Character development through the curriculum: teaching and assessing the understanding and practice of virtue," $J$. Curric. Stud., vol. 00, no. 00, pp. 1-18, 2020. doi:10.1080/00220272.2020.1755996

[42] J. Irmansyah, R. Lumintuarso, F. X. Sugiyanto, and P. Sukoco, "Children's social skills through traditional sport games in primary schools,” Cakrawala Pendidik., vol. 39, no. 1, pp. 39-53, 2020. doi:10.21831/cp.v39i1.28210

[43] "Respect- Results of a Pilot Project Designed to Improve Behaviour in English Football (Brackenridge et al., 2009),” no. April, 2009.

[44] R. Weinberg and D. Gould, "Character Development and Good Sporting Behavior,” Found. Sport Exerc. Psychol., pp. 548-568, 2007.

[45] A. P. Turner and T. J. Martinek, "An investigation into teaching games for understanding: Effects on skill, knowledge, and game play,” Res. Q. Exerc. Sport, vol. 70, no. 3, pp. 286-296, 1999. doi:10.1080/02701367.1999.1060 8047

[46] P. M. Tomme and J. C. Wendt, "Affective Teaching: Psycho-Social Aspects of Physical Education,” J. Phys. Educ. Recreat. Danc., vol. 64, no. 8, pp. 66-70, 1993. doi:10.1080/07303084.1993.10606812

[47] B. Gonçalves, R. Marcelino, L. Torres-Ronda, C. Torrents, and J. Sampaio, "Effects of emphasising opposition and cooperation on collective movement behaviour during football small-sided games,” J. Sports Sci., vol. 34, no. 14, pp. 1346-1354, 2016. doi:10.1080/02640414.2016.1143111

[48] M. Qian and K. R. Clark, "Game-based Learning and 21st century skills: A review of recent research,” Comput. Human Behav., vol. 63, pp. 50-58, 2016.doi:10.1016/j.chb.2016.05 .023

[49] D. O’Connor, P. Larkin, and A. M. Williams, “Observations of youth football training: How do coaches structure training sessions for player development?,” J. Sports Sci., vol. 36, no. 1, pp. 39-47, 2018. doi:10.1080/02640414.2016.1277034

[50] T. Muhtar, T. Supriyadi, and A. S. Lengkana, "Character Development-based Physical Education Learning Model in Primary School,” Int. J. Hum. Mov. Sport. Sci., vol. 8, no. 6, pp. 337-354, 2020. doi:10.13189/saj.2020.080605

[51] A. Lumpkin, “Teachers as Role Models Teaching Character and Moral Virtues," J. Phys. Educ. Recreat. Danc., vol. 79, no. 2, pp. 45-50, 2008.doi:10.1080/07303084.2008.105981 34

[52] S. Yardley, P. W. Teunissen, and T. Dornan, "Experiential learning: Transforming theory into practice,” Med. Teach., vol. 34, no. 2, pp. 161-164, 2012. doi:10.3109/0142159X.2 012.643264

[53] M. Chavan, “Higher Education Students’ Attitudes Towards 
Experiential Learning in International Business,” J. Teach. Int. Bus., vol. 22, no. 2, pp. 126-143. doi:10.1080/0897593 0.2011 .615677 .

[54] G. G. Bower, “Utilizing Kolb’s Experiential Learning Theory to Implement a Golf Scramble,” Int. J. Sport Manag. Recreat. Tour., vol. 12, pp. 29-56, 2013. doi:10.5199/ijsma rt-1791-874x-12c

[55] J. Williams and H. M. Parker, "Integration of experiential learning and leadership development in a sport management classroom,” Sport Manag. Educ. J., vol. 10, no. 1, pp. 54-63, 2016. doi:10.1123/SMEJ.2015-0012

[56] L. Wiersma, "Measurement in physical education and exercise science conceptualization and development of the sources of enjoyment in youth sport questionnaire," Meas. Phys. Educ. Exerc. Sci., vol. 5, no. 3, pp. 153-177, 2001. doi:10.1207/S15327841MPEE0503 